\title{
Risk Factors for Infection After Cardiovascular Surgery in Children in Argentina
}

\author{
Rosanova, Maria Teresa ${ }^{1}$; Allaria, Adrian ${ }^{1}$; Santillan, Alejandro ${ }^{1}$; Hernandez, Claudia ${ }^{1}$; Landry, Luis ${ }^{1}$; Ceminara, Rodolfo ${ }^{2}$ and \\ Berberian, Griselda ${ }^{1}$ \\ ${ }^{1}$ Hospital Garrahan; ${ }^{2 N}$ urse Hospital Garrahan; Buenos Aires, Argentina
}

\begin{abstract}
Infections after cardiovascular surgery are an important cause of morbidity and mortality. This paper described the study of risk factors associated with development of infections. This is a prospective study, setting in a Hospital JP Garrahan, a tertiary and referral center of Buenos Aires, Argentina. All patients with cardiac surgeries between 1/ 11/01 to 1/1/ 2002 were included. The median age of $p$ was 30 months (r: 1-212 m), 184 p (53\%) were boys, 21\% (75) had underlying disease, being the genetic disorders or undernutrition the most frequent, $56 \mathrm{p}(16 \%)$ had previous surgery, $36 \mathrm{p}(10 \%)$ had received previous antibiotics and 30 (9\%) of them had previous infection, An ASA score higher than or equal to 3 was found in $308 \mathrm{p}(\mathbf{8 8} \%)$. Median hospital stay before surgery was $1 \mathrm{day}$ (r1-120 d), $88 \mathrm{p}$ (25\%) nedeed inotropic support with epinephrine, $147 \mathrm{p}(42 \%)$ needed mechanical ventilation during a median time of 4 days (r: 1-66d).Drainage with thorax opened was done in 339p (97\%) for a median time of 2 days (r:1-7d). Total hospital stay was between 1 and 120 days (median 5 days). Postsurgical infections developed in 38 of 350p (11\%). Superficial wound infection in 4 p (1\%), 5 p (1.5\%) had deep infection, 3p (1\%) had mediastinitis and $26 \mathrm{p} \mathrm{(7.5 \% )} \mathrm{had}$ other nonsurgical infections Eleven p (3\%) died. By multivariate study underlying diseases $(\mathrm{p}<0.012)$ OR 4.22 (CI 1.38-12.8), inotropic support with epinephrine ( $p<0.027)$ OR 4.04 (CI 1.17-13.9) and postoperative stay longer than 12 days were found to be risk factors for infections. We concluded that presence of underlying diseases, longer hospitalization and inotropic support were risk factors for infections.
\end{abstract}

Key-Words: Infections, cardiovascular surgery, children.

Postoperative infections are an important cause of morbidity and mortality in children undergoing cardiovascular surgery [1-5]. In adults the risk factors reported were diabetes mellitus, the use of internal mammary artery grafts for bypass conduits and other factors clearly related to age and the nature of the performed operations [6].

There are very few reports in pediatric patients about risk factors for infections after cardiovascular surgery. Many of them only evaluate the risk of infection related with the surgical site [1,6-8]. Identification of risk factors would help to reduce morbidity and mortality and to implement special preventive measures in high risk patients.

This study was undertaken to determine incidence, pathogens and risk factors associated with the development of infections after cardiovascular surgery in children.

\section{Material and Methods}

Prospective chart review was done for all cardiac surgeries performed in children less than 18 years of age at Hospital Nacional de Pediatria J. P. Garrahan (a tertiary and referral center) between November 2001 and December 2002.

Demographic and clinical variables were recorded for all children including age, sex., congenital heart defect (CHD), underlying diseases, preoperative antibiotic use and previous cardiovascular surgery.

Received on 9 May 2009; revised 25 November 2009.

Address for correspondence: Dr. Rosanova Maria Teresa. Barragan 601

Cap Fed Argentina Zip Code 1408. Phone:541145033445. Fax:

541147031188. Hospital Garrahan. Argentina. E-mail: margris2@yahoo.com.ar.

The Brazilian Journal of Infectious Diseases 2009;13(6):414-416. (C) 2009 by The Brazilian Journal of Infectious Diseases and Contexto Publishing. All rights reserved.
American Society of Anesthesiologyst's score (ASA) (9) was determined in every patient. ASA score is an index to asses preoperatively the overall physical status of the patients and ranges from 1 to 5 [9]. We also studied type and time of surgery, bypass time, duration of postoperative, inotropic support with epinephrine and ventilatory support, presence of fever, microorganisms and outcome. We do not evaluated levels of glucose or hypothermia as a risk factors.

Postsurgical infections were defined according to Centers for Disease Control(CDC) [10]. All patients were included in the analysis of infection regardless of the type.

\section{Statistical Analysis}

The Mann-Whitney Rank Sum test was used to assess differences between groups for two continuos variables. Dichotomous variables were analyzed using the Chi- square test (with Yates correction). To estimate the multivariate predictive value of independent covariates a stepwise multiple logistic regression model was used, Degree of fit of the data to model was estimated by the Hosmer- Lemeshow test, and the percentage of the variance was obtained. The predictive value for each covariant was expressed as the odds ratio (OR), a 95\% confidence interval was derived as the standard error of these beta coefficients. Receiver Operating Characteristics curve (ROC curve) was used for cutoff point in continuous variables. Data distribution is expressed as mean $+/$ - standar deviation. Ap value of $\mathrm{p}<$ or $=0.05$ was, considered significant for both extremes. The software used was CSS/ Statistical, 5.1 (Statsoft Corp. Tulsa, Okla, USA) and True Epistat v. 5, 1995 (Richardson, Texas, Usa) [11].

\section{Results}

Three hundred and fifty patients were evaluated in the study. Most frequent CHD were: ventricular septal defects, 
tetralogy of Fallot, atrial septal defect transposition of great vassels $266 \mathrm{p} \mathrm{(76 \% )} \mathrm{and} \mathrm{others} 84 \mathrm{p} \mathrm{(24 \% ).}$

The median age of patients was 30 months (r: 1-212), 53\% (184p) were boys, 21\% (75p) had underlying disease, being the genetic disorders ( $30 p)$ or undernutrition $(45 p)$ the most frequent. Sixteen percent (56p) had previous surgery, $10 \%$ (36p) had received previous antibiotics and 9\% of them (30 p) had had previous infection. An ASA score $\geq 3$ was found in 88\% (308 p), Median hospital stay before surgery was 1 day (r:1-120), the median time of bypass was 69 minutes (r:13-300), $25 \%$ (88) needed postoperative epinephrine for inotropic support, 42\% (147) needed mechanical ventilation during a median time of 4 days (r:1-66). Ninety seven percent (339) of the patients required chest tube drainage for a median time of

Table 1. Characteristics of patients.

\begin{tabular}{lcc}
\hline Variable & $\mathbf{n}$ & $\mathbf{\%}$ \\
\hline Age (median in months) & 30 (R:1-212) & \\
Male sex & 184 & 53 \\
Underlying diseases & 75 & 21 \\
Previous surgery & 56 & 16 \\
Previous antibiotics & 36 & 10 \\
ASA $>$ or =3 & 308 & 88 \\
Inotropic support & 88 & 25 \\
Death & 11 & 3 \\
\hline
\end{tabular}

2 days (r:1-7). Length of hospital stay was between 1 and 120 days (median $5 \mathrm{~d}$ ) (Table 1 ).

Postsurgical infections developed in 38 patients (11\%). Four of them (1\%) were superficial wound infections, 5 patients (1.5\%) developed deep infections, 3 patients (1\%) had mediastinitis and 26 of them (7.5\%) had other nonsurgical infections, being sepsis the most common one. Gram positive cocci were the most frequent pathogens in surgical site infections and Gram negatives bacilli in non surgical infections (Table 2).

Eleven patients (3\%) died. By univariate analysis risk factors for infection were younger age, presence of underlying disease, higher American Society of Anesthesiologist score (ASA), previous infection, postoperative inotropic support with epinephrine, requirement for mechanical ventilation and a postoperative stay in intensive care unit (PICU) stay $\geq 12$ days $(\mathrm{p}<0.05)$ (Table 3$)$.

By multivariate analysis only underlying disease $(\mathrm{p}<0.012)$ OR 4.22 (CI 1.38-12.8), inotropic support with epinephrine $(\mathrm{p}<0.027)$ OR 4.04 (CI 1.17-13.9) and postoperative PICU stay $\geq 12$ days ( $<<0.003)$ OR 1.08 (1.031.14) significantly continued as risk factors for infections (Table 4).

\section{Discussion}

Infections after cardiovascular surgery in pediatric patients are an important cause of morbidity and mortality. Overall rate
Table 2. Type of infections and microorganisms (n: 38).

\begin{tabular}{|c|c|c|}
\hline Type of infections & Total (p) & Microorganisms \\
\hline Surgical site & 12 & $\begin{array}{l}\text { S aureus (5p), Coagulase } \\
\text { negative Staphylococcus } \\
\text { (1p),Pseudomonas } \\
\text { aeruginosa (1p) } \\
\text { Salmonella spp (1p) } \\
\text { Negative cultures (4p) }\end{array}$ \\
\hline Sepsis & 17 & $\begin{array}{l}\text { Pseudomonas aeruginosa (3p) } \\
\text { Nonfermenter Gram negative } \\
\text { rods (1p) } \\
\text { Candida albicans (1p) } \\
\text { Negative cultures (12p) }\end{array}$ \\
\hline $\begin{array}{l}\text { Pneumonia } \\
\text { associated with } \\
\text { mechanical } \\
\text { ventilation }\end{array}$ & 5 & $\begin{array}{l}\text { H,influenzae non b (2p) } \\
\text { Acinetobacter spp (1p) } \\
\text { Negative cultures (2p) }\end{array}$ \\
\hline $\begin{array}{l}\text { Urinary tract } \\
\text { infections }\end{array}$ & 3 & $\begin{array}{l}\text { Pseudomonas aeruginosa } \\
\text { (2p) } \\
\text { Proteus spp (1p) }\end{array}$ \\
\hline $\begin{array}{l}\text { Catheter } \\
\text { associated } \\
\text { bacteremia }\end{array}$ & 1 & $\begin{array}{l}\text { Coagulase negative } \\
\text { Staphylococcus (1p) }\end{array}$ \\
\hline
\end{tabular}

Table 3. Univariate analysis.

\begin{tabular}{lccl}
\hline Variable & $\begin{array}{c}\text { Presence of } \\
\text { infections } \\
\mathbf{( 3 8} \mathbf{p})\end{array}$ & $\begin{array}{c}\text { NO } \\
\text { infections } \\
\mathbf{( 3 1 2} \mathbf{~})\end{array}$ & $\mathbf{p}$ \\
\hline Age & $21.6 \pm 34.6$ & $56.7 \pm 68.2$ & $<0.0005$ \\
ASA score (> or = 3) & 37 & 271 & $<0.001$ \\
Underlying diseases & 24 & 51 & $<0.00001$ \\
Previous infection & 10 & 20 & $<0.0005$ \\
Inotropic support & 31 & 57 & $<0.00001$ \\
Hospital stay ( $>$ 12d) & 33 & 41 & $<0.00001$ \\
Ventilation (days) & $18.2 \pm 17.3$ & $3.9 \pm 4.012$ & $<0.00001$ \\
\hline
\end{tabular}

Table 4. Multivariate analysis.

\begin{tabular}{llll}
\hline Variable & Coef. $\beta \pm$ ES & pvalue & $\begin{array}{l}\text { Odds ratio } \\
\text { (LC 95\%) }\end{array}$ \\
\hline Underlying diseases & $1.440 \pm 0.567$ & $<0.012$ & $4.22(1.38-128)$ \\
Inotropic support & $1.397 \pm 0.628$ & $<0.027$ & $4.04(1.17-13.9)$ \\
Hospital stay more & $0.081 \pm 0.027$ & $<0.003$ & $1.08(1.03-1.14)$ \\
12 days & & & \\
\hline
\end{tabular}

of infections in our serie was $11 \%$. Other reported series showed an overall incidence between 10 and $18 \%$ of infections after cardiovascular surgery [3].

Nonwound infections occurred in $7.5 \%$ of our patients, fewer than that observed by others (Mehta: $11 \%$ and Pollock: $18 \%)$ [3-5]. 
The worldwide incidence of infections related with surgical site is between 0.5 and $7.5 \%$. However we report an incidence of $3.5 \%$ which is lower than the one found by Pollock et al. (7.5\%) [5] and Mehta et al. (5\%) [3] but higher than Edwards et al. who reported $0.5 \%$ [12]. Various risk factors have been proposed for cardiovascular infections Edwards et al. [12] showed that bypass time higher than one hour, postoperative bleeding, need for a new surgery and low cardiac output state persisting $>24$ hours postoperatively, were risk factors for sternal wound infections. They proposed inadequate antibiotic prophylaxis as a risk factor as well.

Pollock et al. [5] associated ocurrence of sternal wound infection to a high PRISM score (Pediatric Risk of Mortality Score).

Mehta et al. [3] showed that younger age, underlying diseases and higher ASA score were risk factors for infections. In some papers prolonged mechanical ventilation was associated with sternal wound infections however Hehrlein et al. [13] did not considered it a significant risk factor.

Postoperative inotropic support was considered an independent risk factor for deep sternal wound infections by Parisian Mediastinitis Group [14].

A longer stay in the PICU after surgery is also associated with sternal wound infections [3]. However it is not clear whether infection might be the cause rather than the consequence for this situation [3]. In our serie postoperative PICU stay $\geq 12$ days was related with all type of infections.

Alpress et al. [1] in a retrospective study showed that age less than 1 month and longer time of surgery were risk factors. It is remarkable that the majority of the above mentioned studies evaluated the risk of infections related with the surgical site only.

Risk factors associated with non surgical site infections were previous infections, emergency surgery, prolonged time of surgery or bypass time, bleeding, postoperative blood transfusion requirements or deferred sternal closure [3]. Alpress et al. [1] reported not correlation between type of cardiopathy and type of infections similar to our findings.

Analyzing the risk factors with logistic regression analysis only the presence of an underlying disease, postoperative inotropic support with epinephrine and postoperative stay in PICU > 12 days were found to be significantly associated with infection at any site.

In summary, infections are an important cause of morbidity and mortality in cardiac surgery patients. The identification of factors for infections could be useful in designing strategies to prevent them.

\section{Acknowledgments}

We would like to thank Janneke Deurloo and Dr Roberto Lede for their help.

\section{References}

1. Allpress AL, Rosenthal GL, Goodrich KM, Lupinetti FM, Zerr DM. Risk factors for surgical site infections after pediatric cardiovascular surgery. Pediatr Infect Dis J. 2004;23:231-4.

2. Mrowczynski W, Wojtalik M, Zawadzka D, Sharma G, Henschke J, Bartkowski R, Pawelec-Wojtalik M, Wodzinski A, Westerski P. Infection risk factors in pediatric cardiac surgery. Asian Cardiovasc Thorac Ann. 2002, 10: 329-33

3. Mehta PA, Cunningham CK, Colella CB, Alferis G, Weiner LB. Risk factors for sternal wound and other infections in pediatric cardiac surgery patients. Pediatr Infect Dis J. 2000 19(10):10004.

4. Montgomery VL, Strotman JM, Ross MP. Impact of multiple organ system dysfunction and nosocomial infections on survival of children treated with extracorporeal membrane oxygenation after heart surgery. Crit Care Med. 2000; 28:526-31.

5. Pollock EM, Ford-Jones EL, Rebeyka I, Mindorff CM, Bohn DJ, Edmonds JF, Lightfoot NE, Coles J, Williams WG, Trusler GA, Geofrey A and Barker A Early nosocomial infections in pediatric cardiovascular surgery patients. Crit Care Med. 1990, 18: 37884.

6. Huddleston CB. Mediastinal wound infections following pediatric cardiac surgery. Semin Thorac Cardiovasc Surg. 2004; 16(1): 108-12.

7. Malviya S, Voepel-Lewis T, Siewert M, Pandit UA, Riegger LQ, Tait AR. Risk factors for adverse postoperative outcomes in children presenting for cardiac surgery with upper respiratory tract infections. Anesthesiology. 2003 98: 628-32.

8. McAnally HB, Cutter GR, Ruttenber AJ, Clarke D, Todd JK. Hypothermia as a risk factor for pediatric cardiothoracic surgical site infection. Pediatr Infect Dis J. 2001; 20(4):459-62.

9. Wolters U, Wolf T, Stützer H, Schroder T. ASA classification and perioperative variables as predictors of postoperative outcome. Br J Anaesth 1996, 77: 217-22.

10. Horan TC, Gaynes RP, Martone WJ, Jarvis WR Enori TG: CDC definitions of nosocomial surgical site infections, 1992: a modification of CDC definitions of surgical wound infections. Am J Infect Control 1992; 20: 271-4.

11. Ruttimann UE: Statistical approaches to development and validation of predictive instruments. Crit Care Clin 1994; 10: 19-34.

12. Edwards MS, Baker CJ. Median sternotomy wound infections in children. Pediatr Infect Dis 1983; 2: 105-9.

13. Hehrlein FW, Herrmann H, Kraus J. Complications of median sternotomy in cardiovascular surgery. J Cardiovasc Surg 1972; 13: $390-3$

14. The Parisian Mediastinitis Study Group. Risk factors for deep sternal wound infection after sternotomy: a postoperative, multicenter study. J Thorac Cardiovasc Surg 1996; 111: 12007 . 